\title{
1 An introduction to understanding digital games
}

\author{
Jo Bryce and Jason Rutter
}

Academic interest in digital games has a history dating back to the early 1980s. Papers such as Hemnes' (1982) consideration of the application of copyright to support creativity in the digital games industry; the work of Sedlak et al. (1982) exploring the development of social integration through recreational programming for people with learning disabilities; the case report by McCowan (1981) of 'Space Invader wrist' (a minor ligament strain which we would probably now refer to as repetitive strain injury [RSI]); and Sudnow's (1983) much neglected book on the process of acquiring 'digital skill', indicate how rapidly researchers were responding to the new leisure technologies. There is also a pre-history that dates back as far as Alexander Douglas' PhD part of which involved what appears to be the development of the first computer game in the early 1950s (see Kirriemuir, Chapter 2) - concerned less with social and cultural factors than elements of technology innovation and system design.

Unfortunately, this resource of digital games analysis is often not fully credited by contemporary authors. For example, Wolf and Perron (2003) suggest that their collection would not have previously been possible because of a lack of academics working on digital games and Newman (2004) suggests that academics have ignored digital games. The trope that digital games have been neglected by researchers and marginalized by the academy is problematic given the lack of substantive evidence provided. There is, of course, a difference between a topic being overlooked and being ignored - there is no malice or intentionality in the former. Suggesting that digital games have not received the academic attention they deserve because they have been framed as 'a children's medium' or 'mere trifles' (Newman 2004: 5) is difficult to 
accept without sources for these accusations. Neither does such a position help us explain how digital games are notably different from other ephemera and mundane practices that researchers have engaged with, such as music (Hatch and Watson, 1974; Sudnow, 1978) or humour (Jefferson, 1979; Sacks, 1978 - even Rutter, 2000).

Despite claims concerning a lack of research on digital games, examining the digital games bibliographies available on the Internet ${ }^{1}$ makes it is clear that research on digital games has for some time been thematically and disciplinary diverse. Perhaps rather than a shift in the structure of academia, the recent surge in publications about digital games reflects the entry of researchers, who grew up in the Pong, Atari, NES and BBC Micro years, into academia.

A failure to address these existing bodies of digital games literature in contemporary research carries with it a number of consequences. First, it removes our ability to build upon this work or, to draw on the sociologists Robert Merton's phraseology, removes from us the possibility to 'stand on the shoulders of giants' (1965: 9). ${ }^{2}$ Second, by not situating research in what has proceeded, work runs the risk of unquestioningly assuming that this research has no precedents. This is a tenuous assumption and one which, unless critically evaluated, runs the risk of undermining contemporary academic research on digital gaming. Exploring a similar theme in the introduction to her collection, Virtual Methods Hine writes about Internet research:

Perspectives for the sociology of scientific knowledge are an important reminder not to take for granted the discontinuities between what we are doing now and what has gone before. These distinctions are achieved in the ways we research and write about the new technologies and the ways in which we organize our disciplinary boundaries. (Hine, 2005: 6-7)

Through recognizing previous work as well as discontinuities and understanding these as a process of academic development and evolution it is, however, possible to show that the amount of research on digital games in growing. A simple search of articles in the ISI Web of Knowledge's database of journal publication shows an almost twofold increase in peer reviewed papers on digital games when comparing the periods 1995-1999 and 2000-2004. In the earlier years there were 275 articles containing the phrases computer games(s) or video games(s) and this rose to 535 during the following five years. While such a comparison may not be scientifically rigorous, it does offer an indication of a significant rise in research and publication activity in the area of 


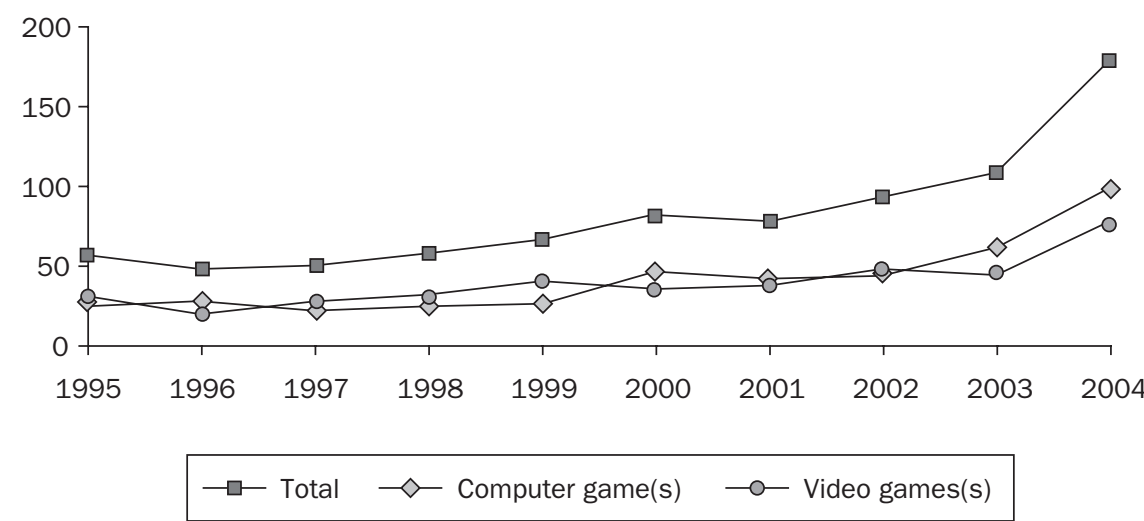

Figure 1.1 Number of digital games articles published, 1995-2004

digital games. This is growth we can expect to be maintained for sometime, especially as research begins to include developments in new areas of technological innovation that have game relevance such as digital television and mobile telecommunications.

This publishing has taken place across disciplines. The growth in papers about digital games across the sciences, social sciences, and the arts and humanities serves to highlight the rich diversity of interest in digital games, as well as the great potential for work that involves cooperation between different disciplines and methodological perspectives. As Wolf and Perron convincingly point out:

[T] he emerging field of video game theory is itself is itself a convergence of a wide variety of approaches including film and television theory, semiotics, performance theory game studies, literary theory, computer science, theories of hypertext, cybertext, interactivity, identity, postmodernism, ludology, media theory, narratology, aesthetics and art theory, psychology, theories of simulacra, and others. (2003: 2)

We could spend time adding systematically to this list but it perhaps more practical to adopt Aarseth's approach which suggests that interest in digital games is so broad that a 'more or less complete list reads like the A-Z list of subjects from a major university' (Aarseth, 2003: 1). Such a perspective highlights how digital games have become of empirical and theoretical interest for an impressively wide range of 
researchers, each of whom bring to the debate a different set of methodologies, theoretical perspectives and questions they seek to answer about/with digital games.

This book is an attempt to pull together the diversity and richness of research on digital games, and the disciplinary tools and approaches that can be used to investigate them. This collection celebrates the fact that research on digital games provides great opportunities for exploring the potential links and divides between the different academic areas, which characterize this emerging disciplinarily diverse field. It attempts to avoid being over prescriptive about developing a single approach or set of methods or theoretical assumptions and is structured to encourage reading across chapters in order to explore the ways in which different disciplines investigate digital games. This approach, we hope, will encourage readers to explore both familiar and innovative paths of research and develop a broad background knowledge with which to investigate digital games, the practices of gaming, and the socio-economic and political factors that facilitate and control it. Our aim is that the chapters will provide the intellectual resources for multidisciplinary digital games research. We hope that the variety of theoretical and methodological approaches outlined by the included authors will provide knowledge of the various disciplinary perspectives available to those exploring the field, and encourage the reader to formulate their own research interests in digital games.

\section{A market context to digital games research}

The growth in digital games research may be a reflection of changes outside academic research. Indeed, the placing of digital games research against the backdrop of the global digital games market is not unusual in writing in the area. The combination of impressive market value and increasingly powerful technology is a frequent starting point in a substantial amount of writing on digital games (Bryce and Rutter, 2003; Kline et al. 2003; Provenzo, 1991).

According to data published by the American-based Entertainment Software Association (ESA, 2005), the US digital games market was worth US $\$ 7.3$ billion dollars ${ }^{3}$ in 2004 . Similar figures suggest that the value of digital games for Europe was $€ 5.6$ billion. ${ }^{4}$ (ELSPA, 2005b) and highlight the UK as the world's third largest market for digital games 
(after the USA and Japan). In the UK software and hardware combined are worth more than $£ 2.2$ billion $^{5}$ (ELSPA, 2005a), with software accounting for $£ 1.2$ billion $^{6}$ of that figure (ELSPA, 2005b). In the UK, digital games account for approximately half of the market for toys and games (Euromonitor, 2004) and, for 2003, the market was estimated at being worth between $£ 1.26$ billion (ELSPA, 2004) and $£ 2.1$ billion (Euromonitor, 2004).

Such figures are almost ritually introduced at the beginning of many publications on digital games research and these figures are indeed impressively large. However, these figures are less frequently placed within a comparative context through which one can understand their implications. As research into digital games continues to grow it is useful to revisit these market overviews and question whether they actually demonstrate as much as we might hope or assume.

To support the idea of digital games as a cultural revolution represented by market worth, headlines in the press and some academic discourses claim that digital gaming is now 'worth more than the television or film industry' (Dimitrov, 2005). However, like many eye catching headlines, such claims only show part of the picture and report data in a slightly more spectacular manner than the generators of the data might be entirely comfortable with. The digital games market is indeed comparable to box office receipts - but this is just one element of revenue generated by the film industry. Recognizing that the market for pre-recorded DVDs in the USA was approximately equal to the global market for box office takings during 2002 places such claims into context. When other film industry revenues are added including hardware sales, video sales and rentals, licences, merchandizing, and so forth, on a global scale, the total market values become much less symmetrical.

Although a rationale for studying digital games is often based upon the reported size of the market, it is seldom made clear that the figures quoted compare to more mundane markets such as insurance, credit card services, large kitchen appliances or fast food. Comparing figures from Euromonitor and other industry sources gives a backdrop to the relative UK and global markets for consumer and business products and services. In the UK, digital games are worth approximately half as much again as 'paints and coatings', while the fast food market is worth about three and a half times more.

Such rankings of market values do not necessarily convert neatly into a similar ordering for unit sales, so we must be careful not to take market value as a proxy for number of people involved in an activity. 
Understanding Digital Games

TABLE 1.1 Value of digital games and other UK markets

\begin{tabular}{lcc}
\hline Market & Annual value & Year $^{\mathbf{1}}$ \\
\hline Credit and charge cards (UK) & $£ 131.7$ billion & 2002 \\
Insurance premiums (UK) & $£ 125.5$ billion & n.d. ${ }^{2}$ \\
Advertising (UK) & $£ 16.2$ billion & 2002 \\
Kitchen appliances (UK) & $£ 13.6$ billion & 2003 \\
Mail order and home shopping (UK) & $£ 12.1$ billion & 2003 \\
DVD sale and rentals (USA) & $£ 11.2$ billion & $2002^{3}$ \\
Box Office (Global) & $£ 11.1$ billion & $2002^{4}$ \\
Digital games (Global) & $£ 10.2$ billion & $\mathbf{2 0 0 2}^{\mathbf{5}}$ \\
Newspapers (UK) & $£ 7.7$ billion & $2003^{6}$ \\
Gambling (UK) & $£ 7.7$ billion & 2003 \\
Fast food and home delivery/takeaway (UK) & $£ 7.4$ billion \\
Footwear (UK) & $£ 5.1$ billion & 2003 \\
Courier services (UK) & $£ 4.8$ billion & 2003 \\
Networking hardware (UK) & $£ 3.0$ billion & 2002 \\
DVD and video software (UK) & $£ 2.9$ billion & 2002 \\
Digital games (UK) & $£ 2.1$ billion & $2004^{7}$ \\
PC business software (UK) & $£ 1.6$ billion & $\mathbf{2 0 0 3}$ \\
Paints and coatings (UK) & $£ 1.4$ billion & 2002 \\
Batteries (UK) & $£ 0.4$ billion & 2003 \\
\hline
\end{tabular}

${ }^{1}$ Year for which the estimate is given rather year of publication of estimate.

${ }^{2}$ Association of British Insurers, see www.abi.org.uk

${ }^{3}$ Converted from Digital Entertainment Group's estimate of US $\$ 20.3$ billion, see http://www.dvd information.com

${ }^{4}$ Converted from Screen Digest estimate of US $\$ 20$ billion, see http://www.screendigest. com/ezine/0311

${ }^{5}$ Converted from Screen Digest (2003) estimate of US $\$ 18.5$ billion.

${ }^{6}$ KPMG, see http.//www.kpmg.co.uk/news/detail.cfm?pr=1954

7 IVF (2004).

For example, whereas the average price for a DVD in Europe is $€ 10.99$ (IVF, 2004), digital games have tended to maintain a relatively high unit price for consumers. A top level console game may have an initial shelf price of almost US $\$ 50 / € 50 / £ 40$, while only older titles released as part of, for example, The Platinum Collection for the PlayStation 2, Xbox Classics, or Players' Choice for the GameCube, have prices comparable to those for general film DVDs.

There has developed a body of work examining digital games as an economic market (see for example Aoyama and Izushi, 2003; Castronova, in press; Hayes and Dinsey, 1995; Kline et al., 2003; Readman and Grantham, 2004), but the success of this work lies in the way it has developed refined and applied analyses to difference aspects of digital gaming and games. Each of these authors has taken a different approach to exploring the economics of the digital games industry, 
rather than justifying their research through headline figures. This differs from work that claims, sometimes implicitly, that digital games markets are notably large, and that this in itself justifies the investigation of their products as cultural artefacts.

Digital games are undoubtedly a successful market showing an impressive year-on-year growth, but this does not make them unique as an object of study - a solely economic rationale for studying games would, objectively, make them less interesting than washing machines and other white goods. However, one of the things that differentiate digital games from many of the other markets in Table 1.1 is that they are a leisure good purchased with disposable income. For both the economist and the socio-cultural researcher this opens up a variety of interesting questions concerning value, consumer choice, networks and so forth that tend to be hidden when relying on reporting market size alone. It is these implications, rather than the absolute value of the market itself, which are perhaps the most interesting of observations to develop.

\section{Digital games as a new research challenge}

A number of authors have argued that digital games present a departure from previous cultural or technological artefacts, and that in order to understand them we much develop a whole new research and practical approach (see, for example, Aarseth, 2003; Eskelinen, 2001; Lowood, 2002). The general rationale of such authors is that digital games present a new use of technology, which is profoundly linked to leisure, creativity and play and, as such, are a unique category without comparison. This has led to claims that, as Wolf (2001: 2) puts it, 'video games are already widespread and unique enough [sic] to deserve their own branch of theory' (Wolf, 2001: 2).

Wolf stresses the aesthetic content of digital games to suggest that research into digital games 'adds new concepts to existing ideas in moving imagery theory, such as those concerning the game's interface, player action, interactivity, navigation, and algorithmic structures' (2001: 3). However, this emphasis on discontinuity prevents any significant comparison with other new technologies. Digital games (or rather their design and play) may well draw on the issues Wolf highlights, but are they really unique in doing so? Do many of these issues have equal relevance to other forms of multimedia design, head-up 
display in fighter planes (or racing driver's helmets) and programming structures in general?

Similarly, Aarseth (2003) argues that digital games are intrinsically different to other types of games. In his manifesto for the study of games he suggests that the aesthetics of games was not studied prior to digital games and, as such, it is digital games that have brought this change as they become 'much closer to the ideal object of the humanities, the work of art ... become visible and textualizable for the aesthetic observer' (2003: 1). While a stark contrast between digital games and their non-digital or earlier equivalents may seem plausible, closer inspection makes this contrast less straightforward. Indeed, when looking at the development of games it is not clear that a simple digital/ non-digital divide is tenable or where the paradigmatic shift, so clear to Aarseth, from 'traditional' to digital contrast takes place. ${ }^{7}$

That digital games are unlike other games or sport in the manner in which they are built upon technology may be true but, made simply, this assertion can hide the fact that leisure and technology have long been linked in their development and practice. This relationship between technology and leisure, whether it be developments in tennis racket manufacture (the use of graphite-reinforced materials) the development (and legislation against) pinball machines in the USA or the use of technology to restrict access to leisure sites, has been discussed elsewhere (see Bryce, 2000).

As a games-related example, think of a simple shooting gallery game, such as one of the numerous Flash and shareware games that can be found on the Internet. As a game, this could be compared and contrasted with a game in which rocks are thrown at cans staked along the top of the fence. It may be clear that the digital game is a technological simulation of the low technology version of the game. In the digital game, technology replaces the physical action of throwing. However, by replacing the rocks with the shooting of an air rifle, we can mediate the throwing action with technology without going digital. A move towards mechanical arcade games, such as Midway's Submarine (in which the player looks through a periscope and 'fires' light at ships which have photosensitive cells on them), further pushes the mediated and simulated aspects of the game. It is also an example of a game that cannot be played outside the technological framework.

Of course, Aarseth is wise enough to refine his rhetoric into a more sustainable understanding of what digital games might be through his idea of 'games in virtual environments' which would include 'games from Tetris via Drug Wars to EverQuest, while computerized toys like 
Furby and dice and card games like Blackjack are excluded. Noncomputerized simulation games like Monopoly or Dungeons and Dragons would not be excluded' (Aarseth, 2003: 2). However, by shifting his definition Aarseth, intentionally or not, elides the definition of a phenomenon with his own interest in it. An understanding of game aesthetics that excludes games that have a massive user base-such as the version of Solitaire, which has been packaged with successive versions of Microsoft Windows, or online poker, which with US \$15 billion of revenue in 2003 (McClellan, 2004), is worth a similar amount as the entire digital games industry - runs the risk of using a definition of games which does not actually include the majority of digital game playing.

This again highlights how drawing boundaries around academic fields is not necessarily a productive activity. Separating the aesthetic study of digital games for research into the aesthetics of other games such as 'the beautiful game' of football/soccer (Inglis and Hughson, 2000) - does not necessarily help engage with that research, nor does it support mutual understanding with research carried out in other fields, which may provide insights for the study of digital games.

\section{'Digital games studies' or multidisciplinary research?}

The social sciences have long recognized that research methods, whether scientific or social scientific, are not neutral. Based upon empirical, theoretical and philosophical investigation researchers have argued that there is no simple way of separating science from the doing of science (Hine, 2002; Latour and Woolgar, 1986; Lynch, 1993; Merton, 1973). Kuhn (1962) has shown that when doing 'normal science' practitioners operate with a general set of shared assumptions governing how science is done, what understandings it is based upon and the world view it represents. However, at times anomalies may occur that call into question this previous paradigm, and present possible new and competing ones. An example of this was the shift from the understanding of space as one in which the Earth was the centre of God's creation, around which other heavenly bodies moved in perfect circles, to a heliocentric model of the solar system with planets having elliptical paths. The idea of paradigmatic shifts has been associated with the manner in which science, disciplines and accepted discourses develop not in a neutral fashion but through political and academic struggle. 
Some researchers have argued that research on digital games has the power to cause paradigmatic shifts within a range of academic disciplines and that existing disciplines lack the tools, theory or application to fully address the research needs of understanding digital games. These writers have argued for the establishment of something that might be called 'computer game studies' (Raessens and Goldstein, 2005), 'video game theory' (Wolf and Perron, 2003) or 'games studies' (Aarseth, 2001), but which exists outside the established disciplines of academic research.

Perhaps the most famous proponent of this perspective has been Espen Aarseth. In his inaugural editorial for the online journal Game Studies, Aarseth (2001) drew a proverbial line in the sand, which he warned researchers not committed to establishing a new research discipline about crossing. He accused researchers from outside his own field of 'colonising' game studies:

The greatest challenge to computer game studies will no doubt come from within the academic world. Making room for a new field usually means reducing the resources of the existing ones, and the existing fields will also often respond by trying to contain the new area as a subfield. Games are not a kind of cinema, or literature, but colonising attempts from both these fields have already happened, and no doubt will happen again. And again, until computer game studies emerges as a clearly self-sustained academic field. To make things more confusing, the current pseudo-field of 'new media' (primarily a strategy to claim computer-based communication for visual media studies), wants to subsume computer games as one of its objects. (2001)

Aarseth is clear that the attempt to build game studies as a new and separate field is as a political as well as academic project. Indeed, an interesting aspect of Kuhn's paradigmatic shifts - as with the evolution of new fields, disciplines and university departments - is not merely the scientific change that underpins it but the recognition that such changes will profoundly benefit a few and disadvantage others. With new fields come funding investment, new professorial posts and other resources, as well as decisions about what forms the central core of the field.

Whether or not research into digital games will consolidate into a distinct field remains to be seen, but we can be certain that: (1) it will not happen without active work toward creating a hierarchy of digital games research and digital games researchers; (2) it will not happen without the institutionalization of what lies within and without the 
new field; and (3) it will not happen without the formation of academic practice that accepts certain methodologies and rejects others; focusing on certain aspects of digital games while marginalizing competing viewpoints.

However, given the academic, industrial, consumer and administrative diversity of digital games, would the reification of this dynamic research field be a productive endeavour, or does such movement seek to kill the enthusiasm, innovation and interdisciplinarity that currently characterize a great deal of digital games research?

Would it serve to prevent engagement with the broader development in academic interest in ephemeral issues of modern life from the visual (Ball and Smith, 1992; Emmison and Smith, 2000), the auditory (Bull, 2000; Bull and Back, 2003) and issues of taste (Bourdieu, 1984: Warde, 1997). While it has been argued that the study of digital games has changed certain academic institutions, it is possible to view the growth in digital games research as simply part of a broader evolution of academic investigation into the routine and often taken-for-granted aspects of cultural life.

Discussing the development of cultural studies, David Morley, who with his colleagues at Birmingham University was highly influential from the 1970s onwards in laying the foundations for what we now regard as (British) cultural studies, warned of the dangers 'of the installation of a particular orthodoxy' (Morley, 1992: 2). Warning of the difficulties in prematurely drawing boundaries around research areas and translating findings from one area to another (academically, culturally and geographically) he argued:

It would seem today, especially in the context of the North American Academy, cultural studies not only has become almost synonymous with a certain kind of postmodern theorizing but is now also referred to ... simply as 'theory'. This fetishization of a rather abstract idea of theory is quite at odds with what Stuart Hall has described as the 'necessary modesty' which academic work in this field should properly display. (1992: 3)

Is the overenthusiasism of academic digital game researchers to create new disciplines around their own research concerns stoping the growth of research ideas? Is the keenness of some to erect boundaries around research into digital games only going to serve in making multidisciplinary work harder to develop? Will this isolationism retard the development of new ideas and maintenance of relevance to industry 
and policy users? Taken as a whole, the academic diversity of this collection would argue so.

The chapters in this book come from a diverse set of academic disciplines. One of their notable aspects is not that the authors compete for ownership of digital games research or present their own fields as providing definitive insight into digital games, but that they use the work from their own areas to enable them to answer different questions about the same phenomenon. The reader of this book is not asked to pick which of the viewpoints presented is correct to the exclusion of others, but to understand the multifaceted nature of digital games and that research methods and analysis must be chosen in line with the specific questions that one seeks to explore. For example, no amount of ethnographic-style participation observation with gaming communities and playing of digital games will help understand the economic models upon which the contemporary digital games industry is based. Of course, the converse is also true. Objectively, neither perspective is more useful until we decide which part of digital gaming we want to explore and the most appropriate methods for doing so. The chapters in this collection highlight the manner in which digital games do not exist in a space hermetically sealed from other aspects of culture, society and economics, but that they are a product of them and contribute to their reproduction and development.

While for convenience we can simplify our model of the world of digital games, draw largely arbitrary boundaries around the aspects we are most interested and build our analysis on defined assumptions, factoids and simplifications, it is important to be clear that these are products of our analysis are not the object of analysis itself. While it is often necessary for practical reasons to limit the focus of our investigation or simplify complex phenomena, it is good practice to remember that these boundaries are part of the research process and the questions and methods that we choose to ask. By focusing on a specific element of digital games, whether that be the technology; the onscreen text; the programmed text; the communities that are part of digital games; or their use in education, we deepen our understanding of the area. However, without sharing ideas with others outside specific research niches, we risk losing sight of the bigger picture upon which each niche depends for it structure.

One of the reasons why digital games have proved such a dynamic source of research and analysis in recent years is the manner in which they sit at a junction between a wide range of established academic interests. As Alloway and Gilbert point out: 
Video game narratives and the practices associated with video game culture form part of a complex interplay of discursive practices. They do not stand alone. They are part of a network of discourses and social practices that similarly construct violence, aggression, gender relations, ethnicity and power. It is because they dovetail so easily that they become so easily 'naturalized' in cultural practice. (1998: 96-7)

By unreflexively giving priority to one aspect of digital games we run the risk of convincing ourselves that our own perspective is, in actual fact, the defining one. While trying to understand digital games we must be aware of avoiding the situation of the six wise (but blind) men in John Godfrey Saxe's poem. ${ }^{8}$

Confronted with an elephant these men touch upon different part of the animal and make the mistake of assuming that what they have found represents the whole of the creature. As such, the first man feels the elephants side and assumes elephants are like walls; the second touches the tusk and so thinks the elephant is like a spear; the third concludes the elephant is like a snake having grabbed the moving trunk; the fourth, feeling the elephant's knee asserts the animal is like a tree; the fifth finds the elephant's ear and so believes the animal to be like a fan; and the final wise man finds the rope-like tail. Saxe warns that with the knowledge gathered:

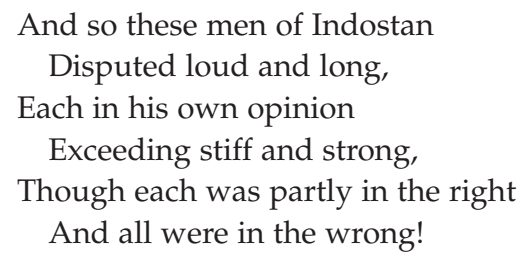

The lesson here, is not that any of the wise men were wrong in what they discovered or how they understood it, but rather that they did not see further than their own area. They assumed that their area could define the whole object and were prepared to take this partial knowledge as evidence of the ultimate perspective. In our attempt to gain a cohesive picture of digital games it is important that we show a keenness to talk to our fellow researchers and work together to develop and a deeper understanding of our behemoth. This collection is an attempt to support and encourage such dialogue in order to strengthen our understanding of digital games. 
Understanding Digital Games

Relevant web sites

Association for Business Simulation and Experiential Learning www.absel.org

Bristol Dyslexia Centre, Net Educational Systems www.dyslexiacentre. co.uk

Buzzcut www.buzzcut.com

Digiplay Initiative www.digiplay.org.uk

DiGRA (Digital Games Research Association) www.digra.org

DiGRA's digital games conferences www.gamesconference.org

ELSPA (Entertainment and Leisure Software Publishers Association) www.elspa.com

Euromonitor www.euromonitor.com

ESA (Entertainment Software Association) www.theesa.com

Games and Culture - A Journal of Interactive Media www.sagepub.com/ journal.aspx?pid=11113

International Association for Game Education and Research (IAGER) www.iager.org

IGDA (International Game Developers Association) www.igda.org

Hard Core www.digra.org/index.php?topic=HardCore

International Game Journalists Association (IGJA) www.igja.org

International Journal of Intelligent Games \& Simulation www.scit.wlv.ac. uk/\%7Ecm1822/ijigs.htm

ISAGA (International Simulation \& Gaming Association) www. isaga.info

ISI Web of Knowledge isi22.isiknowledge.com

Interactive Software Federation of Europe www.isfe-eu.org

Journal of Game Development www.jogd.com

MEF (Mobile Entertainment Forum) www.m-e-f.org

Slashdot Games games.slashdot.org

TIGA (The Independent Games Developers Association) www.tiga.org

\section{Notes}

1 See, for example, http://www.digiplay.org.uk/books.php, http://www.renreynolds.com/bibliography.htm or game-research.com/reference.asp.

2 This idea was revisited by Merton's son, Robert C. Merton, during his banquet speech on the occasion of his award for the Nobel prize for economics in 1997. See http:// nobelprize.org/economics/laurcates/1997/merton-speech.html

3 Approximately $€ 5$.8 billion or $£ 4$ billion. 
4 Approximately US $\$ 7$ billion or $£ 3.9$ billion.

5 Approximately US $\$ 4$ billion or $€ 3.2$ billion.

6 Approximately US $\$ 2.2$ billion or $€ 1.7$ billion.

7 What Aarseth's means by 'traditional' here is unclear but, like using 'natural' to mean 'usual' or refer to that which appears normal, care should be shown in not using 'traditional' when referring not actually to traditions but something which is chronologically earlier than now. For example, the traditions associated with playing the dreidel game at Hanukkah are not the same as those associated with an Easter egg hunt. Similarly, a historical view provides a different insight into understanding that traditions linked to lacrosse as a game played by Native Americans, as well as the differences in the UK between rugby league (traditionally a working class sport) and rugby union (the traditional choice of public, that is fee paying, schools).

8 Saxe's poem, 'The Blind Men and the Elephant' is based upon a tale originally Chinese or Indian in origin although its exact heritage is unclear. A Buddhist version can be found in the Udana but Hindu versions are recorded and the story illustrates well the Jain notion of Anekanta - the multi-faceted nature of reality.

\section{References}

Aarseth, Espen (2001) 'Computer game studies, year one', Game Studies, retrieved 15 March 2005 from: http.//www.gamestudies.org/0101/editorial.html

Aarseth, Espen (2003) 'Playing research: methodological approaches to game analysis', paper presented at MelbourneDAC, the 5th International Digital Arts and Culture Conference, 19-23 May 2003, Melbourne.

Alloway, N. and Gilbert, P. (1998) 'Video game culture: playing with masculinity, violence and pleasure', in S. Howard (ed.), Wired-up: Young People and the Electronic Media. London: UCL Press. pp. 95-114.

Aoyama, Y. and Izushi, H. (2003) 'Hardware gimmick or cultural innovation? Technological, cultural, and social foundations of the Japanese video game industry', Research Policy, 32 (3): 423-44.

Ball, M. and Smith, G.W.H. (1992) Analyzing Visual Data. London: Sage.

Bourdieu, P. (1984) Distinction: A Critique of the Judgement of Taste. London: Routledge.

Bryce, J. (2000) 'The technological transformation of leisure', Social Science Computer Review, 79, 1-16.

Bryce, J. and Rutter, J. (2003b) 'Gender dynamics and the social and spatial organisation of computer gaming', Leisure Studies, 22: 1-15.

Bull, M. (2000) Sounding Out the City: Personal Stereos and the Management of Everyday Life. Oxford: Berg.

Bull, M. and Back, L. (eds) (2003) The Auditory Culture Reader. Oxford: Berg.

Castronova, E. (in press) Synthetic Worlds: The Business and Culture of Online Games. Chicago, IL: University of Chicago Press. 
Dimitrov, A. (2005) 'Influence of video games on children's health', American Family physician, 71 (8). Retrieved 21 November 2005 from www.aatp.org/atp/ 20050415/lettersonline.html

ELSPA (2004) 'Video games continue to grow', press release, 6th January 2004, retrieved 15 March 2005 from: www.elspa.com/about/pr/pr.asp? mode $=$ view $\& \mathrm{t}=1 \& \mathrm{id}=405$

ELSPA (2005a) 'The UK games industry is in session', retrieved 15 April 2005 from: www.elspa.com/about/pr/pr.asp?mode=view\&t=1\&id=528

ELSPA (2005b) 'The games industry: a UK success story', retrieved 15 April 2005 from: www.elspa.com/about/pr/pr.asp?mode=view\&t=1\&id=524

Emmison, M. and Smith, P. (2000) Researching the Visual: Images, Objects, Contexts and Interactions in Social and Cultural Inquiry. London: Sage.

Eskelinen, M. (2001) 'Towards computer game studies', Digital Creativity, 12 (3): 175-83.

ESA (2005) 'Essential facts about the computer and video game industry', retrieved 26 May 2005 from: www.theesa.com/files/2005EssentialFacts.pdf

Euromonitor (2004) Toys and Games in UK. London: Euromonitor International.

Hatch, D.J. and Watson, D.R. (1974) 'Hearing the blues: an essay in the sociology of music', Acta Sociologica, 17: 162-78.

Hayes, M. and Dinsey, S. (1995) Games War: Video Games - A Business Review. London: Bowerdean Publishing Company Ltd.

Hemnes, T.M.S. (1982) 'The adaptation of copyright law to video games', University of Pennsylvania Law Review, 131: 171-233.

Hine, C. 2002 'Cyberscience and social boundaries: the implications of laboratory talk on the Internet', Sociological Research Online, 7 (2), retrieved 15 April 2005 from: www.socresonline.org.uk/7/2/hine.html.

Hine, C. (ed.) (2005) Virtual Methods: Issues in Social Research on the Internet. Oxford: Berg.

Inglis, D. and Hughson, J. (2000) 'The beautiful game and the proto-aesthetics of the everyday', Cultural Values, 4 (3): 279-97.

IVF (2004) 'European video market: the industry overview', retrieved 15 April 2005 from: www.ivf-video.org/EuropeanOverview2004.pdf

Jefferson, G. (1979) 'A technique for inviting laughter and its subsequent acceptance/ declination', in G. Psathas (ed.), Everyday Language: Studies in Ethnomethodology. New York: Irvington. pp. 79-96.

Kline, S., Dyer-Witheford, N. and de Peuter, G. (2003) Digital Play: The Interaction of Technology, Culture, and Marketing. Montreal: McGill-Queen's University Press.

Kuhn, T.S. (1962) The Structure of Scientific Revolutions. Chicago, IL: University of Chicago Press.

Latour, B. and Woolgar, S. (1986) Laboratory Life: The Construction of Scientific Facts. Princeton, NJ: Princeton University Press.

Lowood, H. (2002) 'Shall we play a game: thoughts on the computer game archive of the future', retrieved 15 April 2005 from: www.stanford.edu/\%7 Elowood/Texts/shall_game.pdf 
Lynch, M. (1993) Scientific Practice and Ordinary Action: Ethnomethodology and Social Studies of Science. Cambridge: Cambridge University Press.

McClellan, J. (2004) ‘The hot favourite', Guardian Unlimited, retrieved 15 April 2005 from: http://sport.guardian.co.uk/horseracing/story/0,10149, 1182988, 00.html

McCowan, T.C. (1981) 'Space invaders wrist', New England Journal of Medicine, 304: 1368.

Merton, R.K. (1965) On the Shoulders of Giants. New York: Free Press.

Merton, R.K. (1973) The Sociology of Science: Theoretical and Empirical Investigations, ed. N.W. Storer. Chicago, IL: The University of Chicago Press.

Morley, D. (1992) Television Audience and Cultural Studies. London: Routledge.

Newman, J. (2004) Videogames. London: Routeldge.

Provenzo, E.F. (1991) Video Kids: Making Sense of Nintendo. Cambridge, MA: Harvard University Press.

Raessens, J. and Goldstein, J. (eds) (2005) Handbook of Computer Game Studies. Cambridge, MA: MIT Press.

Readman, J. and Grantham, A. (2004) 'Strategy frameworks and the positioning of UK electronic games super developers', Centre for Research in Innovation Management working paper, University of Brighton, retrieved 15 April 2005 from: http://centrim.mis.brighton.ac.uk/publications/abstracts/ 041abs.shtml

Rutter, J. (2000) 'The introductions of stand-up performers: comparing comedy compères', Journal of Pragmatics, 32 (4): 463-83.

Sacks, H. (1978) 'Some technical considerations of a dirty joke', in J.N. Schenkein (ed.), Studies in the Organization of Conversational Interaction. New York: Academic Press. pp. 249-70.

Sedlak, R.A., Doyle, M. and Schloss, P. (1982) 'Video games - a training and generalization demonstration with severely retarded adolescents', Education and Training in Mental Retardation and Developmental Disabilities, 17: 332-6.

Sudnow, D. (1978) Ways of the Hand: The Organization of Improvised Conduct. Cambridge, MA: Harvard University Press.

Sudnow, D. (1983) Pilgrim in the Microworld. New York: Warner Books.

Warde, A. (1997) Consumption, Food and Taste: Culinary Antinomies and Commodity Culture. London: Sage.

Wolf, M.J.P. (ed.) (2001) The Medium of the Video Game. Austin, TX: University of Texas.

Wolf, M.J.P. and Perron, B. (2003) The Video Game Theory Reader. London: Routledge. 
